\title{
O Plano de Remuneração
}

\author{
FUNDAMENTOS TEÓRICOS E TÉCNICA
}

\section{ENNOR DE ALMEIDA CARNEIRO}

(Técnico de Administração)

O trabalho, que ora se divulga, faz parte de um cíclo de reuniões promovidas pela Seção de Estudos do Plano de Classificação da Divisão de Pessoal do D.A.S.P. As palestras levadas aefeito contaram com a colaboração dos especialistas que trabalharam no Plano de Classificação de Cargos, e tiveram por objetivo promover o treinamento do pessoal que, nos diversos Ministérios, deverá ser incumbido da aplicação daqueles princípios, quando da efetivação do aludido Plano, atualmente em trânsito no Congresso Nacional .

$O$ estudo que apresentamos a seguir foi elaborado pelo Técnico de Administração ENNOR DE ALMEIDA CARNEIRO, na 5 a $^{\text {a }}$ reunião, e aborda o assunto em seus principais aspetos, ou seja, em seus fundamentos teóricos e características de técnica e metodologia.

$\mathrm{P}$ RELIMINARMente, quero congratular-me com a Divisão de Pessoal do D.A.S.P., especialmente com a sua Seção de Estudos do Plano de Classificação de Cargos pela idéia oportuna e feliz da instituição dêstes semináriơs. Ainda por outro lado devo dizer que vim para esta reunião entendendo - e creio data venia, que entendi bem - que não iria pròpriamente fazer uma conferência. Gostaria portanto que emprestássemos a esta reunião um caráter inteiramente informal, encarando-a como a autêntica mesa-redonda que deve ser e para onde haveremos de trazer, cada um de nós, a sua contribuição. Estou certo de que muito mais poderei eu aprender ouvindo as críticas e observações que aqui certamente serão formuladas, de que tentando ensinarThes o que os senhores talvez conheçam da experiência vivida nos seus respectivos ministérios. Aqui estou, por conseguinte com o simples propósito de tentar uma interpretação do projeto de Classificação de Cargos que tramita no Congresso Nacional, especialmente na parte relativa ao Plano de Remuneração, - à luz da experiência que adquiri por ocasião da elaboração do mesmo. Com efeito, tendo trabalhado como Assessor Técnico da Comissão 
de Classificação de Cargos, no Setor do Plano de Remuneração, e estando assim bastante familiarizado com o andamento das pesquisas que para êsse efeito se empreenderam. é êsse o único motivo capaz de justificar a minha presença, no momento, entre os senhores. Minha missão deve limitar-se, por um lado, à tarefa de expor os métodos de trabalho adotados pela Comissão para levar a efeito aquelas pesquisas e, por outro lado, demonstrar como fcram alcançadas as soluções propostas no projeto.

Antes, porém, de iniciar a exposição objetiva do roteiro de trabalho seguido pela Comissão, cujas linhas mestras figuram no mapa existente à página 22 do Diário do Congresso, permitam-me fazer uma pequena introdução, de ordem mais ou menos teórica, que considero indispensável para uma perfeita compreensão da matéria:

Inicialmente abordemos a questão da diferenciação e correlações existentes entre o Plano de Classificação, pròpriamente dito, e o Plano de Remuneração.

Creio que os palestradores que me precederam já tiveram oportunidade de esclarecer êsse assunto. Convém insistir, todavia, em que Plano de Classificação de Cargos e Plano de Remuneração constituem, ambos, assuntos correlatos, paralelos, fortemente entrosados, mas que se não devem, nem podem confundir, visto adotarem técnicas diferentes e se destinarem a uma finalidade imediata, também diferente.

Essa a razão por que a Comissão se bipartiu em dois setores principais: uni de Classificação de Cargos outro de Remuneração.

Em síntese, poderíamos dizer que a Classificação de Cargos tem por objetivo oferecer ao Administrador ou Chefe Executivo um retrato conjunto das unidades de trabalho - comumente denominadas carǵos - existentes na organização que dirige. A finalidade dêsse estudo é permitir aơ Chefe Executivo a realização eficiente das diversas fases da administração do pessoal - a seleção, o "placement", a promoção, o treinamento. Uma dessas fases, certamente, é o regime de remuneração. Dentre elas, aliás, o problema da remuneração é o que mais imperiosamente exige, para ser bem conduzido, o concurso prévio de um plano racional de Classificação de Cargos. Os senhores todos têm experiência de como o tratamento emprestado ao problema da remuneração, no serviço público federal, se tem revelado falho, distanciado da realidade e constantemente tumultuado por reestruturações isoladas, nem sempre justificadas com a desejável clareza. Na Revista do Serviço Público de abril do corrente ano, em artigo intitulado "Regime de Remuneração", tentamos um estudo objetivo das condições de remuneração que hoje prevalecem no Serviço Civil. A respeito seria oportuno lembrar que a própria reforma de 1936, que sem dúvida representa um passo adiantado para disciplinamento dos salários, está hoje em dia totalmente desfigurada pelas constantes e profundas alterações parciais nela introduzidas. Tudo isto se deve a que na ausência de um plano de classificação de cargos racional, a questão da remuneração só pode ser tratada em bases hipotéticas e falhas.

Até bem pouco tempo a remuneração do trabalho recebia, - não só no Serviço Público, como na Indústria, - um tratamento muito pouco realístico. Quase poderia dizer-se que era deixada ao capricho do Chefe Exe- 
cutivo que dela se servia para favorecer os amigos ou atender às exigências de políticos influentes. Para ilustrá-lo bastaria recordar um comentário que recentemente $\mathrm{li}$, em livro de autor norte-americano, e que me calou muito fundo pela autenticidade da crítica que veicula. Dizia o autor que havia bem poucos anos atrás o processo de administração de salários nas emprêsas privadas, nos E.U.A. podia ser resumido na frase com que um gerente respondeu ao pedido de aumento de um empregado: "Dou-lhe um níquel de aumento se você prometer não contar nada a ninguém".

Soluções parciais e improvisadas, como a dêsse exemplo, não mais se justificam nos nossos dias. O problema, que efetivamente se reveste de uma importância econômico-social das mais sérias, vem sơfrendo grande evolução, acentuadamente dos meados do Século XIX a esta parte. Os importantes movimentos de idéias e as transformações políticas dos últimos 50 anos fixaram especial atenção no problema da explơração do trabalho humano. Com efeito, os salários pagos aos trabalhadores freqüentemente se situavam em nível inferior ao necessário para satisfazer às necessidades mínimas da subsistência.

Na Encíclica famosa "De Rerum Novarum" - Papa LEÃo XIII pregava - salário justo. O Tratado de Versalhes, aliás subscrito pelo Brasil, acompanhando a evolução do pensamento filosófico-cristão, incorpora aos seus postulados básicos a dignificação dơ trabalho humano e preceitua: "a trabalho igual deve corresponder salário igual". Os trabalhadores na indústria e no comércio começam a unir-se em sindicatos e a impor condições confortáveis de trabalho e niveis condignos de remuneração. Têm início os acôrdos coletivos de trabalho - o "collective bargaining", - cuja importância na evolução da política de salários não pode ser descurada. A respeito gostaria de sugerir, aos que acaso não lêem inglês, $\alpha$ exame de um trabalho que publiquei na Revista do Serviço Público de janeiro último, intitulado - "Salário e Relações Humanas no Trabalho". Nesse artigo procurei descrever a maneira como surgiram e se desenvolveram as uniões de trabalhadores e o modo como funcionam os "acôrdos coletivos", entre empregados e empregadores, destinados a fixar padrões de remuneração.

Vemos, depois disto, os empregadores forçados a dedicar ao problema da remuneração uma atenção diferente. Começam a surgir, na indústria, estudos muito sérios, destinados a resolver o problema em bases toleráveis sem acarretar o encarecimento do custo dơs produtos. A situação conduz a conseqüências então imprevisíveis. A fim de permitir a fixação de niveis adequados de remuneração do trabalhador e atender aos reclamos incessantes das Uniões, viu-se a indústria na contingência de reduzir o custo da produção, o que determinou a revisão das técnicas de fabricação e a demanda pela racionalização do trabalho. E' a revolução industrial, de que os senhores certamente conhecem as principais características.

Os planos racionais de remuneração têm exatamente por objetivo estabelecer, para certa comunidade de trabalho. diversificada pela natureza e importância das tarefas que executa, um regime de salários capaz de atender aos imperativos da justiça social, ao mesmo tempo fixando normas adequadas à obtenção do máximo rendimento no trabalho. Só é possível alcançar êsse desiderato através dos regimes de estímulo funcional, que se expressam pela justa distribuição dos salários segundo a contribuição de cada um. 
A história do industrialismo contemporâneo testemunha que nos Estados Unidos grande número de greves se evitaram desde o momento em que o regime de salários se difundiu como resultado de um trabalho científico, baseado na real avaliaçãa das funções.

A adoção de tais providências não resulta de um mero tecnismo improdutivo. Prova-o, aliás, a experiência norte-americana. EDWARD B. SHILS, da "Philadelphia Steamlines Personnel Plan" observava, em 1943, que os trabalhadores municipais, nos E.U.A., ameaçavam entrar em greve se um plano de classificação não fôsse imediatamente adotado, sôbre o qual se baseassem cs novos padrões de vencimento. Eis aí a conveniência dos planos de classificação reconhecida pelo próprio trabalhador, como instrumento indispensável para a elaboração de um sistema satisfatório de remuneração.

Assim, quando o trabalhador, compelido pelas contingências da conjuntura econômica faz sentir com mais acentuada ênfase a sua insatisfação, de pouco ou nada valerão as elevações puras e simples de salário, que fatalmente mantêm os desnivelamentos existentes e agravam as injustiças anteriores ao se traduzirem por aumentos indiscriminados. A única medida corretiva aconselhável em tais casos é a elaboração de um plano de remuneração capaz de assegurar um relacionamento lógico entre os diversos niveis de responsabilidades e dificuldades das funções, o que na realidade só será possível após a elaboração de um bem cuidado plano de classificação que the sirva de infraestrutura.

Note-se, com efeito, que salário justo e salário igual são, daqui por diante, as duas pedras fundamentais que haverão de condicionar a política governamental de remuneração.

O Estado intervém nas disputas entre empregados e empregadores, ora protegendo e estimulando o "collective bargaining", ora legalizando os sindicatos, depois admitindo o direito de greve, e afinal postulando a participação dos empregados nos lucros das emprêsas e impondo níveis obrigatórios de salário mínimo. Eis, por conseguinte, o Estado influindo diretamente no disciplinamento dos salários e portanto se obrigando a dispensar idêntico tratamento aos seus próprios servidores.

Aqui surge, porém, uma indagação.

Como saber quando o trabalho é efetivamente igual, a fim de fazer jus a salário igual? Está equacionado o problema cuja solução reside na análise do cargo, a qual apurando as analogias existentes entre os diversos cargos, permite a fixação de padrões equânimes de remuneração.

Resta considerar outro importante aspecto da matéria. Sempre que se fala em remuneração no Serviço Público deve ter-se como pressuposto fundamental o interêsse soberano da Administração.

E' um princípiơ muitas vêzes esquecido pelo funcionalismo, geralmente prêso à concepção errônea de um conflito entre ơ seus interêsses e os interêsses da Administração. No Serviço Público, porém, Administração e Funcionalismo não se podem colocar em posições antagônicas. A Administração Pública... "são os seus servidores", escreveu alguém, com muita razão. 
O que deve prevalecer, portanto ${ }_{\text {A }}$ é o interêsse da Administração e por interêsse da Administração se quer significar o interêsse da coletividade. Os cargos públicos não são sinecuras. A preocupação fundamental do Govêrno deve ser a obtenção do máximo rendimento do trabalho. E' um imperativo econômico. Está provado, entretanto, que o maior rendimento do trabalho se obtém através da cooperação espontânea do trabalhador. Daí as modernas teorias de incentivo funcional, política de estímulo, etc., definitivamente aceitas como o único meio eficaz de assegurar que os empregados trabalhem com efetivo desejo de cooperar. Entre os diversos processos de estímulo está a adoção de um regime de remuneração verdadeiramente equânime: "salário igual para trabalho igual". Vê-se portanto, que a recomendação do Tratado de Versalhes não é simplesmente uma conquista de valor social, mas igualmente um imperativo de boa lógica e de técnica de administração, ainda quando se deseje colocar o problema em têrmos absolutamente utilitários.

E' preciso notar, por outro lado, que a preocupação do empregado não está ùnicamente voltada para o montante de dinheiro que recebe, mas, e sobretudo para a relação que existe entre o seu salário e o salário pago aos cơmpanheiros que executam trabalho idêntico.

Daí decorre que, além da análise dos cargos, que nos dá a conhecer o conteúdo funcional de cada ocupação, deve-se lançar mão de um segundo processo de trabalho: a avaliação dos diversos cargos uns em relação com os outros. Em diversas oportunidades, através de artigos na Revista do Serviço Pública e aulas que tive ensejo de ministrar nos Cursos de Administração do D.A.S.P., insisti sempre na necessidade de distinguir com perfeita clareza êstes dois instrumentos de trabalho: a análise e a avaliação. A respeito eu me permitiria ainda uma vez pedir a atenção dos senhores para um trabalho de minha autoria, inserido na Revista do Serviço Público de agôsto de 1954. e intitulado "Avaliação de Cargos", cuja leitura poderia esclarecê-lós melhor, e cujo maior mérito reside no fato de ser um dos poucos estudos - talvez mesmo o único - feito sôbre a matéria em língua portuguêsa.

Tentemos, entretanto, rápida discussão do assunto. A análise do cargo permite descrever com minúcia as suas características funcionais; representa, por assim dizer, um retrato em profundidade, uma radiografia do cargo. A avaliação, porém, é de fato um juízo de relação, e implica na afirmativa de que entre dois cargos dados, um dêles vale mais - se me permitem a expressão - do que o outro. A avaliação é portanto a tarefa de comparar os cargos já analisados, para verificar qual dêles excede aos demais em complexidade de deveres, dificuldade de execução, nível de responsabilidades, etc.

A remuneração deve ser fixada tendo em vista essa avaliação comparativa. Portanto, a análise e a avaliação são dois elementos fundamentais para que possamos estabelecer um sistema satisfatório de remuneração.

Note-se que o fato de conhecermos perfeitamente dois objetos, o fato đe os têrmos analisado, descrito, numerado, classificado, não é suficiente para que possamos atribuir a cada um dêles um valor ou um preço. Assim o comerciante que tem para vender uma mesa e uma cadeira, embora conheça perfeitamente a mercadoria, precisa avaliá-la para poder apreciá-la. Note-se, também, que o fato de a mesa ser maior ou mais pesada do que a cadeira não 
significa necessàriamente que deva custar mais caro. A primeira pode ser fabricada de madeira ordinária e a segunda de madeira rara. Aquela poderá ser uma peça simples de marcenaria e esta uma obra de arte, altamente trabalhada. A primeira tôsca, a segunda envernizada... e assim por diante. A comparação entre uma e outra, ou melhor, entre os elementos de caracterização de uma e outra - denominamos avaliação. E', como antes observamos, um juízo de relação, um juízo comparativo. O mesmo se dá com a remunevação do trabalho. O salário também. sob certo ponto de vista, é um preço, que só podemos fixar depois de avaliarmos as diferentes funções, comparando-as - ou comparando os seus elementos constitutivos.

Ainda hoje li, num jornal da manhã, a notícia de que o Grêmio dos Oficiais Administrativos e Escriturários apresentaria ao Congresso um memorial a título de contribuição para o estudo do projeto de Classificação de Cargos ali em andamento. Não li êsse memorial e o comentário que vou fazer é apenas em tôrno do que no jornal se noticiou. Diz o comentarista que os Oficiais Administrativos e Escriturários pediam a atenção do Congresso para o fato de que no Projeto havia erros palmares, como, por exemplo. o de colocar no mesmo nível de salários o Datilógrafo e o Cozinheiro. O comentarista insistia nesse particular, lembrando ao Congresso Nacional que o Datilógrafo necessita possuir conhecimentos vários, inclusive de Matemática (sic) para o perfeito desempenho de suas funções. Ainda que tenhamos por exato dizer-se que o Datilógrafo precisa conhecer Matemática para preparar tabelas e quadros, - afirmação que merece algumas reservas - verdade será igualmente que o cozinheiro precisa conhecer Matemática para seguir, com rigor. as indicações sôbre a dosagem de certos condimentos nas receitas culinárias. Isto será especialmente verdade se êsse cozinheiro trabalhar num hospital de doenças do aparelho digestivo, onde a alimentação dos doentes deve variar de acôrdo com as recomendações expressas do dietista. Daí a necessidade da avaliação comparativa. Quando fazemos essa avaliação, um dos fatôres constitutivos do cargo, que geralmente consideramos, é o denominado "Repercussão do Êrro". Digam-me os senhores: em qual dêsses dois cargos c êrro acaso cometido pode acarretar transtornos mais graves?" Outro fator que, via de regra, se toma em consideração, na avaliação, é o chamado "Condições materiais do trabalho". Por tal se entende o ambiente físico e as condições de confôrto naturais ao local onde o trabalho é executado. No caso daquelas duas ocupações referidas, teríamos de confrontar as condições de trabalho existentes num escritório, com as que geralmente prevalecem numa grande cozinha de hospital. Pergunto: "onde as condições são mais confortáveis e portanto o trabalho menos cansativo ou irritante"?

Na crítica formulada; e que acabamos de discutir, o equívơco reside precisamente no desconhecimento do papel que representam as técnicas de avaliação - para a correta fixação dos níveis de remuneração.

Pressuposta, portanto, a existência de um plano de classificação de cargos, defronta, daí por diante, o administrador, o sério problema de fixar os níveis de salário. 
Já vimos que o salário, em sua concepção técnica e social, deve contemplar a eficiência individual e simultâneamente garantir um mínimo razoável de subsistência.

O problema seria resolvido pela concessão de um salário base (mínimo) seguida de uma parcela variável, para atender às diferenciações individuais. São os sistemas de remuneração por peça, segundo os quais a parte variável do salário oscila na conformidade do número de unidades produzidas.

Muito se têm discutido êsses sistemas de remuneração. Todos, de modo geral, muito complexos, têm constituído motivo de longas digressões doutrinárias e técnicas. O salário varia, nêles, proporcionalmente ao esfôrço despendido. Receberam por isso, a condenação de alguns, que vêm nêles um meio de transferir, econômicamente, para o trabalhador, parte dos riscos da produção. $\mathrm{O}$ argumento não pode ser pacificamente invocado. $\mathrm{Na}$ realidade os riscos finais permanecem com o empregador. As flutuações do mercado, com suas conseqüências fatais sôbre o preço de venda, não preocupam ao trabalhador. Condenam-nos os moralistas sob a alegação de que levam ao esgotamento físico, uma vez que obrigam o trabalhador a um esfôrço acima d: que a curva normal da fadiga poderia permitir. Alega-se que a produção mínima exigida do trabalhador, para fazer jus ao salário base, tem sido por vêzes fixada em nível tão elevado, que o operário não consegue jamais alcançar uma remuneração satisfatória. O argumento é, ainda aqui, discutível. $\mathrm{O}$ inconveniente pode solucionar-se desde que se estabeleçam taxas adequadas, o que tem sido conseguido por vêzes através da pressão das Uniões de trabalhadores ou pela intervenção do Estado.

Foi, aliás, para anular êsses inconvenientes que se elaboraram os sistemas de salário com prêmio, - Halsey. Bideaux, Rowan e outros, - segundo cs quais cada tarefa corresponde a uma unidade de tempo, dentro da qual o empregado hábil pode, supostamente, executá-la. Quando o trabalhador consegue reduzi-la, produz uma economia de tempo que, traduzida em dinheiro, é dividida entre êles e o empregador.

Ainda nesses sistemas, contudo, permanece de pé um problema - a determinação do tempo base dentro do qual a tarefa deverá ser executada.

A aplicação da teoria do salário de subsistência para determinação da remuneração correspondente à parte fixa levanta a questão fundamental de chegar-se a um entendimento comum sôbre o que deva admitir-se por padrão mínimo de subsistência, ou em outras palavras: quais as necessidades elenientares do trabalhador? O problema não oferece dificuldades inamovíveis, enquanto cogitamos apenas das utilidades materiais mensuráveis: roupa, moradia, etc. Quando abordamos os itens relativos à recreação, aos equipamentos domésticos de uso cotidiano, e outros de avaliação subjetiva, eis-nos em face de um dilema. Resta, ainda, considerar se o "living wage concept" deve admitir variações relativamente ao número de filhos que cada empregado possui e às variações de custo de vida de região para região. O progresso tecnológico. por outro lado, introduz modificações fundamentais nas condiçōes de vida, aumentando o número das necessidades elementares e tumultuando, dêsse modo, todos os cálculos de padrão de vida antes elaborados. 
Em que pêsem, entretanto, tais considerações, ao cuidar do estabelecimento dos sistemas de remuneração do servidor público ainda novas dificuldades se apresentam. O funcionário público, dada a natureza específica de suas funções, não pode ser remunerado na base da produção quantitativa. Ainda mesmo nas atividades privadas, os sistemas de remuneração por peça não são indistintamente estendidos a todos os empregados. Quando, dada a natureza do trabalho, os sistemas de remuneração na base de produção individual se apresentam inadequados, o regime adotado é, então, o do salário em função do tempo, ou em outras palavras, subentendem a compensação paga ao servidor pelo trabalho prestado durante um determinado período.

De modo geral o salário mensal é adotado quando as exigências de qualificação para o exercício da função são de tal ordem a tornarem difícil ou dispendiosa a substituição mais ou menos rápida do servidor.

Segundo JoHN W. RIEgel no seu livro "Salary Determination", caracterizam preponderantemente o trabalho remunerado na base de tempo os seguintes elementos:

a) informações confidenciais;

b) custódia de bens ou dinheiro;

c) proteção dos interêsses do empregador no tratamento de assuntos com terceiros;

d) trabalho puramente intelectual.

Convém, ainda, salientar que o trabalho técnico, de gerência e de aconselhamento, é tìpicamente de caráter evolutivo e sempre afetado pela modificação das condições que o determinam. As pessoas responsáveis por êsse tipo de função são permanentemente solicitadas a sugerir e propor melhoramentos de tôda a ordem. O seu "status" funcional a sua própria estabilidade no serviço, como aliás assinala o autor invocado, depende mais da sua competên. cia e daquilo que dêles se poderá esperar, do que pròpriamente da necessidade imediata ou temporária de seus serviços. E' lógico pois, que os seus trabalhơs não sejam compensados na base da produção momentânea, uma vez que a contribuição que dêles se espera é, realmente, imensurável.

A remuneração do funcionalismo público, ipso-facto, a fim de alcançar a satisfação daqueles requisitos antes enumerados - mínimo ètica e econômicamente razoável e estímulo funcional eficaz - exigem que o problema seja encarado em função de fatôres diferentes dos que se aplicam quando a retribuição pode ser estabelecida na base simples da unidade de produção.

Assim, diferentes métodos de incentivo hão de ser intrơduzidos, e êstes se atingem, via de regra, por dois caminhos: a elaboração de um esquema de remuneração capaz de contemplar os servidores paralelamente: a) pelas qualificações intelectuais e de habilitação comuns ao cargo que ocupam e b) pela eficiência pessoal, maior ou menor, com que se desincumbam das tarefas inerentes à sua ocupação. Neste ponto entram em cogitação os regimes de promoção e aumentos de salário. Daí por que o problema da promoção nấo pode dissorciar-se completamente do problema de remuneração. Daí, igualmente, 
par que o projeto, ora em estudo no Congresso Nacional, teve de estabelecer o sistema de promoções do funcionalismo.

O tratamento do problema da remuneração do servidor público exige, contudo, o estudo de numerosos outros aspectos específicos.

Um sistema sadio de remuneração terá, primeiramente, de levar em conta uma grande variedade de fatôres que nem sempre se apresentam quando a situação é encarada do ponto de vista do empregador particular. Nenhum dêsses fatôres, entretanto, pode ser isoladamente considerado. Constituem parte de um conjunto, onde todos contribuem de um modo, ou de outro, para informar a estrutura que deve ser dada ao plano de remuneração.

O sistema de salários adotado nas Emprêsas privadas, a política de remuneração vigente nas demais entidades públicas, a capacidade financeira do erário, são elementos básicos cujo estudo, muito complexo - de ordem. econômica, administrativa e fiscal - geralmente se efetiva através de uma análise pormenorizada que abrange várias etapas: o levantamento do custo de vida nas diversas regiões do país em relação com o orçamento médio de uma família padrão; a pesquisa estatística dos padrões de remuneração que prevalecem nas Emprêsas privadas; idem com relação às Repartições Públicas dos três níveis de govêrno - Federal, Estadual e Municipal - para as ocupações similares àquelas existentes na Unidade onde se pretende estabelecer o novo plano; o exame retrospectivo da política de pessoal adotada nessas organizações e seus efeitos passados sôbre o moral dos servidores a fim de poder aquilatar a eficácia relativa que demonstraram possuir; o exame das fôlhas de pagamento vigentes a fim de conhecer a maneira como se comportam face às condições financeiras do Empregador e às previsões da receita orçamentária.

Além destas, outras influências concorrem para imprimir determinada orientação à nova estrutura que se deseja emprestar ao sistema. O salário đas "altas autoridades governamentais, por exemplo, (Presidente da República, Congressistas, Ministros de Estado), cujos padrões são prèviamente fixados em lei, determinam e condicionam o teto-limite da remuneração a ser atribuída ao funcionário de carreira.

Por outro lado, o empenho em propiciar meios eficazes à obtenção do desejado rendimento do trabalho impõe a observação de certos princípios normativos, entre os quais conviria destacar:

a) fixação de um nível de remuneração suficientemente elevado pará assegurar estímulo funcional ao servidor;-

b) relacionamento efetivo do salário com o trabalho executado;

c) uniformidade lógica do plano;

d) relação rigorosa e inequívoca entre o salário de uns e outros cargos de diferente ou análogo conteúdo ocupacional.

Estabelecidos êsses pressupostos doutrinários resta examinarmos, com a possível meticulosidade, os processos e as técnicas de trabalho seguidas pela Comissão nas importantes pesquisas realizadas e que precederam a formula- 
ção do plano de remuneração finalmente encaminhado ao Congresso Nacional.

Com efeito, a incumbência de elaborar um plano de remuneração para todos os cargos abrangidos pelo Plano de Classificação significava, verdadeiramente, a introdução no país de uma nova política governamental de salários. Já vimos, com efeito, a complexidade dos fenômenos econômicos e sociais que influem, direta ou indiretamente, no desenvolvimento de um plano apropriado de remuneração.

Era natural, por conseguinte, que a primeira preocupação da Comissão consistisse em indagar até que ponto o regime em vigor levava na devida consideração a existência daqueles fenômenos.

Era imperioso, portanto, que quaisquer conclusões a serem de futuro, fcrmuladas, se estribassem numa análise conscienciosa do sistema vigente de remuneração. Entretanto, a fim de poder determinar se o Govêrno Federal compensava os seus servidores de maneira adequada, impunha-se a necessidade de pesquisar os níveis de salário que vigoravam, para ocupações similares, nas organizações privadas ou públicas estranhas ao Govêrno da União.

Não se conhecem, todavia, procedimentos padrões para a coleta, compilação, cálculo e apresentação de dados dessa natureza. Existem, certamente. princípios científicos que norteiam a realização de quaisquer pesquisas dêsse gênero, os quais fazia mister observar-se para obter resultados válidos.

A avaliação dos cargos, etapa preliminar na elaboração dos planos de remuneração é, como já discutimos em outra oportunidade, o instrumento hábil para permitir a colocação dos diversos cargos em níveis capazes de refletir o valor relativo de cada um. Não obstante, a fim de estabelecer $\alpha$ quantitativo de remuneração a ser atribuído aos diversos níveis é indispensável converter os valores abstratos, obtidos pela avaliação, em valores monetários, na forma de salário.

A avaliação, de fato, como já tenho dito, se exprime por um juízo de relação. Por ela se saberá que o cargo " $X$ " deverá ser remunerado numa proporção de $1: 4$ (um para quatro) em relação ao cargo "Y". Assim, pois, o cargo "X" poderá estar no nível "1" e o cargo "Y" no nível " 4 "; ou aquêle no nível "2" e êste no nível "8".

Como, entretanto, determinar os valores efetivos dêsses níveis?

A pesquisa dos salários correntes na comunidade é o instrumento mais comumente utilizado para êsse fim. E' preciso convir em que os dados sôbre salário, provenientes de fontes diversas, refletem, até certo pontó, o próprio julgamento dos empregados sôbre o valor competitivo de suas atribuições.

A conveniência de utilização dêsse método é matéria pacífica. Já em fevereiro de 1929, há portanto quase 30 anos, nos Estados Unidos da América, o Personnel Classification Board, no seu famoso "Report of Wage and Personnel Survey", dando conta da ampla e importante pesquisa realizada em obediência às determinações do Welch Act, salientava:

"The belief that the rates of pay of Federal workers should be in harmony with those prevailing in other lines of endeavor for the kinds of work 
is so general that it was felt it was of prime importance to make a comprehensive study of the salaries now paid to persons in commercial and industrial establishments, schools and colleges, States and Municipalities, and other organizations employing individuals in positions similar to those found in the Federal Service". (p. 63).

Vejamos, agora, outro aspecto do problema.

Quando se cogita do estabelecimento de levantamentos dessa ordem, dois são os métodos geralmente seguidos: a remessa de questionários pelo correio e a entrevista pessoal. O sistema de questionários está sujeito a limitações evidentes, e $\sigma$ resultado das pesquisas por êsse modo empreendidas deve ser utilizado com a necessária cautela.

O método que melhor atinge os objetivos de um inquérito dessa natureza é, certamente, o da entrevista direta, na qual os recenseadores ficam habilitados a colhêr, a seu próprio critério, as informações que julgarem methor utilizáveis. A Comissão fơi, entretanto, forçada a colocar de lado a idéia inicial de adotar êsse processo, premida pelas contingências do tempo e alertada pelo custo insustentável que inevitàvelmente acarretaria.

A Comissão optou portanto, pela adoção de um sistema misto, de questionário e entrevista. As deficiências técnicas, comuns ao método de questionário, ficavam, assim, até certo ponto, superadas. Entretanto, embora utilizando o questionário como veículo de informações. não foram os mesmos simplesmente postados no correio, mas entregues, em mãos, por entrevistadores especialmente treinados para a missão de orientar os informantes sob a maneira de preenchê-los, assegurando-se, assim, a maior fidelidade possível nas respostes.

Isso pôsto, o instrumento a que me refiro não é, a rigor, o questionário, embora assuma forma semelhante. E' antes o que deveríamos chamar um mapa de registro, cujo preenchimento é controlado in loco.

- Recebidos de volta êsses mapas ou questionários, devidamente preenchidos, seriam os mesmos objeto de cuidadosa tabulação, passando a constituir uma amostragem bastante representativa dos níveis de remuneração correntes na área coberta pelo levantamento.

De qualquer forma porém, por que fôsse conduzida a pesquisa, apresentaria sempre limitações inevitáveis, que o analista precisava não olvidar, ao tentar a apresentação diagramática dos dados coletados. Entre as possíveis falhas poderíamos assinalar:

$1^{\circ}$ ) o número de companhias pesquisadas poderia não corresponder a uma amostragem realmente fiel, uma vez que não é possível cobrir in totum a zona pesquisada;

$\left.2 .^{\circ}\right)$ as informações fornecidas poderiam, por desinteligência ou receio de parte do informante, não representar, com fidelidade a situação existente;

$\left.3 .^{\circ}\right)$ os quesitos formulados poderiam ser inadequadamente interpretados pela Emprêsa informante, ficando parcialmente comprometida, por êsse modo, a validade do resultado. 
As firmas entrevistadas possuem, com frequêencia, uma tal variedade de cargos que a validade dos dados obtidos fica na dependência de haver o informante identificado, com suficiente clareza, os títulos por que são os mesmos designados. E, por isso mesmo, sempre evitado o simples emprêgo do título para designar as funções sôbre as quais se pretende colhêr informações. Como todos sabem, aliás, ocupações de conteúdo ocupacional marcadamente diferenciado, por vêzes se apresentam sob o mesmo título, em diferentes, ou na mesma Companhia. Por outro lado, certas funções, de modo geral idênticas, se designam, em determinadas Emprêsas, por denominaçōes diferentes. Quando tais desinteligências ocorrem, os dados fornecidos perdem a desejada uniformidade e pode ficar comprometido o resultado do inquérito.

A utilização de uma descrição sumária dos cargos sôbre os quais se desejam informações propicia maior certeza de obtenção de dados homogêneos. Ainda, entretanto, quando essa providência acauteladora é tomada, dúvidas sôbre-restam relativamente à validade dos dados obtidos, cuja exatidão repousa no eventual acêrto e clareza com que a descrição tenha sido preparada, e na interpretação que dela façam as fontes inquiridas.

Assim é que além do questionário e das pormenorizadas instruções que o acompanharam, a validade do resultado ficava ainda na dependência de um contato pessoal, bem sucedido, com as emprêsas informantes.

A fim de obter respostas de valor incontestável era imprescindível que das firmas a serem entrevistadas se obtivesse a mais viva e interessada cooperação. Aliás ninguém ignora que a maneira mais hábil de assegurar essa cooperação se apresentu, via de regra, por ocasião do contato inicial. O entrevistador precisa conquistar a confiança do entrevistado. A fim de tornar satisfatórios êsses contatos foram adotadas as seguintes medidas:

$\left.10^{\circ}\right)$ escolher funcionários responsáveis para a delicada tarefa de entender-se com os representantes da firma entrevistada;

$2 .^{\circ}$ ) - aplicar todo o tempo e o esfôrço necessários ao sucesso dessa aproximação;

3. ${ }^{\circ}$ respeitar e manter em caráter sigiloso os dados objeto de coleta.

Com êsse objetivo, a Comissão decidiu solicitar a cooperação do Conselho Nacional de Estatística (Instituto Brasileiro de Geografia e Estatística), cujo pessoal, experimentado nesse mister, haveria de facilitar, em grande parte, a execução dessa tarefa. Por outro lado, tendo em vista que as emprêsas comerciais se mostram geralmente receosas de revelar dados de natureza econômico-financeira, a colaboração do I.B.G.E., instituição tradicionalmente ligada a recenceamentos dêsse tipo, seria, como foi, uma garantia de sigilo, capaz de abrir caminho ao sucesso das aproximaçóes.

No que respeita à escolha da área a ser coberta pelo levantamento, é ela geralmente limitada ao distrito geográfico onde se localiza a organização que empreende a pesquisa - no caso o Serviço Público Federal. Dentro dêsses limites efetivamente se situa o mercado de trabalho de onde advêm a mãode-obra de que a mesma se utiliza. A delimitação dessa zona é, em geral, determinada pela existência de características comuns, v.g., facilidades de transporte, equivalência do custo de vida, etc. 
No caso típico do Serviço Público Federal que, funcionando em todo o território nacional, estende o seu campo de recrutamento a tôdas as regiões do país, essa área necessitava ser, evidentemente, ampliada. O inquérito abrangeu, portanto, a quase totalidade do território brasileiro, tomando-se, porém, as capitais dos Estados como área representativa das diversas regiões geo-econômicas do país.

Uma pesquisa efetuada com êsses cuidados haveria certamente de consumir longo tempo à Comissão.

A verdade, porém, é que quando a amostragem é adequada, e os dados possuem valor estatisticamente incontroverso. ficam automàticamente justificados o tempo e o esfôrço consumidos. Num levantamento de gênero do que se devia empreender, extensivo a, pràticamente, todo o território nacional, a idéia de incluir na pesquisa a totalidade das firmas existentes seria tarefa ingente e talvez improdutiva. Na impossibilidade de fazê-lo, selecionaram-se algumas companhias, na base da população operária respectiva. Esse critério contudo, é bơm salientar. está condicionado à importância econômica da região onde a emprêsa se localiza. Em numerosas áreas sói acontecer que as firmas mais representativas do sistema de salário vigente possuem número restrito de empregados. Isto geralmente ocorre nas pequenas capitais. A inclusão dessas firmas no levantamento está, entretanto, òbviamente justificada .

Aliás, a amostra adequada, selecionada de uma determinada área, é a expressão estatística fiel do comportamento médio de tôda a área.

Em que pese, não obstante, a mais acurada seleção das amostras, esforços especiais tinham de ser empreendidos no sentido de obter dados sôbre cargos que se pudessem rigorosamente comparar àqueles existentes na organização entrevistadora, no caso o Serviço Público Federal. Constitui, êste problema, um dos mais relevantes da pesquisa. Os cargos públicos pelo menos em sua grande maioria, diferem substancialmente daqueles existentes nas organizações privadas. Tornava-se, pois, necessário, proceder à seleção de um númtro razoável de ocupações representativas, sôbre as quais deveria recair a comparação.

Aos cargos por tal forma selecionados dá-se, geralmente, a denominação de "classe-chave", porque, finda a pesquisa, e conhecido o nível de salário corrente com que são os mesmos remunerados no campo das atividades privadas, servirão de guia para a fixação comparativa dos vencimentos dos demais cargos no Serviço Público Federal que, pela sua tipicidade, não encontrem correlatos nas atividades não governamentais.

Outro aspecto da pesquisa sôbre salário corrente que não devia, nem foi descurado é o relativo aos níveis de remuneração das funções congêneres existentes nas administrações Estadual e Municipal. A pesquisa necessàriamente se estendeu a êsse ângulo do problema.

Ao cuidar, entretanto, do levantamento dos níveis de salário, não era possivel evitar de estender a pesquisa ao estudo das numerosas formas de vantagem adicional que, embora não constituindo parte integrante dơ salário, figura como instrumento relevante de incentivo funcional, porque facilita a tarefa do recrutamento e garante a manutenção, em serviço, de pessoal qua- 
lificado. Refiro-me aos chamados benefícios adicionais, capitulados no Estatuto dos Funcionários Públicos Civis da União na parte relativa às vantagens: licença, aposentadoria e outros.

São múltiplos e complexos, como se vê, os problemas técnicos envolvidos pela implantação de um trabalho de pesquisa sôbre salários. A tarefa exigia o concurso de uma equipe altamente especializada. Impunha-se à Comissão planejar o levantamento, escolher o tipo de informações a serem solicitadas, recrutar, selecionar e instruir considerável grupo de auxiliares para efetuar a distribuição dos questionários e orientar. pessoalmente, os informantes, sôbre a maneira de preenchê-los.

Pareceu, portanto, aconselhável, obter assessoramento técnico para a tarefa especializada de estudar e selecionar os métodos e processos de trabatho que se deveriam seguir na realização das pesquisas.

Constituiu-se para isso um setor especializado da Comissão: o "Setor do Plano de Remuneração", o qual deveria incumbir-se, de imediato, das seguintes tarefas: balho;

a) preparação de planos para a coleta de dados no mercado de tra-

b) elaboração de questionários;

c) elaboração de instruções detalhadas para o preenchimento dos questicnários;

d) treinamento dos servidores que deveriam orientar os informantes sôbre o preenchimento dos questionários;

e) estudar os questionários preenchidos;

f) estudar, em cooperação com o I.B.G.E., a tabulação conveniente dos daclos coletados;

g) analisar as características típicas de certo número de cargos públi$\cos$, representativos, a fim de selecionar as classes-chaves necessárias à efetivação do levantamento;

h) preparar a especificação sumária das referidas classes-chaves;

i) compilar, analisar e interpretar os dados obtidos, a fim de fornecer as bases para fixação do novo plano de remuneração;

j) orientar a preparação de quadros estatísticos e diagramas demons. trativos do resultado final das pesquisas;

k) estudar e propor o esquema e tabela final de salários do Plano de Remuneração.

O resultado final do levantamento efetuado está expresso nos quadros e gráficos que acompanham o projeto ora em curso no Congresso Nacional e de que os Senhores poderão obter um exemplar com o coordenador destas reuniões.

Vejamos, agora, a rotina dos trabalhos executados e os processos particulares de análise seguidos no exame dos dados coletados.

Primeiramente, estabelecidas as bases para a realização do levantamento, traçou a Comissão, em função do limitado tempo de que dispunha para 
conclusão dos estudos de que ficou incumbida, um roteiro de trabalho, que é o que figura à pág. 22 do Diário do Conǵresso. Simultâneamente e tão loga o 3 trabalhos preliminares de separação e análise dos questionários do Plano de Classificação de Cargos se revelou em fase adiantada, iniciaram os técnicos a escolha e determinação das classes-chaves que deveriam constituir objeto de comparação.

Três critérios deveriam presidir à se'eção dêsses cargos:

a) serem cargos de bem definida especificação;

b) zerem cargos de um tipo fàcilmente encontrável nas atividades privaสas;

c) serem cargos representatives dos vários e diversificados grupos ie ocupações existentes no Serviço Público Federal.

Constituía ainda outra preocupação da Comissão cuidar com que as intormações sôbre salários fôssem correspondentes à retribuição daquelas funções logo após o ingresso do servidor a fim de que os dados fornecidos pudessem equivaler ao que se entende, na sistemática de pessoal no Serviço Público Federal, por classe inicial de carreira. A razão desta providência é óbvia, visto que a idéia central da pesquisa era obter dados sôbre a remuneração adequada da função e não sôbre o salário do ocupante eventual da mesma em dado momento da sua vida funcional.

Ésse intento se efetivou não sòmente através das instruções detalhadas expeđidas para preenchimento dos questionários, mas pelo próprio cuidado empregado na técnica de descrição das referidas classes-chaves, para a qual se tornava necessária, por conseguinte uma redação final satisfatória: sucinta, clara, objetiva e ao mesmo tempo inteligível para os ocasionais informantes das emprêsas particulares, em geral pouco familiarizados com a nomenclatura adotada no Serviço Público.

Exemplos típicos dessas especificações encontram os senhores à página n. ${ }^{\circ} 34$, do Diário do Congresso citado.

Ultrapassado êste período preparatório, imprimiu-se imediato avanço ao trabalho com a fixação das áreas que deveriam ser cobertas pela pesquisa.

Inicialmente, levantou a Comissão um quadro demonstrativo da freqüência de localização dos funcionários federais pelas Capitais dos Estados e principais Municípios; com relação a êstes últimos procurou-se obter igualmente informações relativas aos índices de população respectiva.

A análise dêstes informes confirmou em definitivo a convicção de que a pesquisa deveria limitar-se às Capitais dos Estados, providência que sôbre economizar o tempo e as verbas disponíveis, ficava justificada em virtude do número restrito de servidores lotados nas cidades do interior, exceção feita de raríssimos Municípios onde se localizam organizações industriais do Estado. Estas exceções, todavia, não conduziam a nenhuma nova conclusão, de vez que nessas regiôes os salários predominantes seriam provàvelmente influenciados pelo nível dos vencimentos pagos aos próprios servidores federais. 
Fixadas, por êsse modo, as zonas geográficas a serem cobertas pelo estudo, passou a Comissão ao exame do segundo aspecto do problema, a seleção das firmas a serem individualmente entrevistadas.

Por certo a inclusão no levantamento de tôdas as firmas localizadas na região escolhida transformaria a pesquisa em tarefa ingente e talvez inútil, dada a pouca expressão estatística que algumas dessas firmas por certo apresentariam.

Algum critério diretivo deveria, entretanto, fixar-se.

Ainda nesta fase pareceu conveniente efetuar um levantamento prévio, destinado a revelar os tipos de emprêgo existentes nos diversos gêneros de estabelecimentos particulares. Para essa amostragem selecionaram-se as Cápitais de São Paulo e Paraná e o levantamento, efetuado segundo dados fornecidos pelo I.B.G.E., pode ser conhecido pelo exame do mapa que figura. à página 33 do Diário do Congresso.

Concluída essa fase preparatória, apenas restava elaborar os questionârios destinados ao registro das informações. Longo período de debates se consumiu na elaboração dêsses instrumentos básicos do inquérito. Atingida porém. essa etapa dos trabalhos, de que se encontrarão os modelos em anexo ao Relatório da Comissão, empreendemos a tarefa de estabelecer as normas e métodos para a apuração dos dados ali, porventura, compilados.

Decidiu-se que a primeira etapa deveria consistir na revisão e crítica dos queștionários do ponto de vista da consistência geral. A revisão teria por objetivo identificar quaisquer falhas provenientes da maneira como tivessem os mesmos sido preenchidos e sanar interpretações acaso divergentes das classes-chaves.

Como resultado dessa análise os questionários seriam classificados em dois grupos:

1. $\left.^{\circ}\right)$ Aquêles considerados aceitáveis e em condições de ser imediatamente tabulados;

2. ${ }^{\circ}$ Aquêles considerados deficientes, sob qualquer aspecto e que, por isso mesmo, estivessem a exigir verificação. Os questionários enquadrados neste segundo grupo deveriam ser devolvidos para revisão, in 1oco, sempre que possível, na conformidade de instruções específicas que seriam para cada caso expedidas.

Em seguida todos os salários indicados deveriam ser convertidos a uma base padrão de tempo de trabalho semanal (trinta e três horas ou quarenta horas, dependendo da maior ou menor freqüência com que êsses números aparecessem nos questionários). Os salários indicados na base hora, dia, semana, quinzena, mês ou ano, seriam todos, uniformemente, convertidos à base mensal.

Os salários indicados em base horária $5 \%$ abaixo ou acima do padrão semanal escolhido não necessitariam ser convertidos.

O valor mensal, total dos auxílios de manutenção assim consideradas as refeições, uniformes, etc. recebidos pelo empregado, seria adicionado ao salário mensal resultante da conversão de que trata o parágrafo anterior e o 
total assim obtido para cada empregado se registraria em espaço apropriado, - reservado à Comissão.

Estabelecidas por êsse modo certas normas para estudo dos questionários, enfrentou a Comissão o problema de selecionar pessoal habilitado à realização das entrevistas.

Selecionados os instrutores, bem como o grupo de recenseadores que deveria incumbir-se da visita às firmas localizadas no Distrito Federal, ficaram os técnicos da Comissão encarregado's de ministrar-lhes cuidadoso treinamento especializado, o que se fêz através de várias reuniões onde eram minuciosamente estudados os questionários e fornecidas pormenorizadas instruções sôbre a maneira como deviam os mešmos proceder na realização do inquérito.

Em seguida se elaboraram e transmitiram instruções específicas sôbre a maneira de preenchê-los. Advertiu-se que o entrevistado não deveria colhêr informações sôbre ocupações outras que não constassem da relação das clas, ses-chaves. Explicou-se que para identificar uma determinada ocupação, dentro da emprêsa entrevistada, o entrevistador deveria guiar-se pelas descrições de classes-chaves para êsse efeito preparadas. Uma vez. porém, identificada a ocupação deveria registrá-la pelo título que the correspondesse na relação, e não por aquêle pelo qual o referido emprêgo fôsse eventualmente conhecido na emprêsa entrevistada. O entrevistador deveria ainda certificarse de que o emprêgo para o qual estava pesquisando as bases de salário fôsse realmente enquadrado em todos os sentidos (e respeitados, se possível, todos os detalhes), dentro de alguma das descrições constantes da relação. Pediuse-lhes que, em nenhuma hipótese, se deixassem guiar pela simples verossimiIhança de títulos de ocupações. Fêz-se empenho em lembrar que tôda fidedignidade do levantamento dependeria do cuidado emprestado pelo entrevistador à seleção dos tipos de emprêgo nesta fase do trabalho. Solicitou-se dos mesmos que não incluíssem nos questionários informações relativas ao salário de empregados cujas autênticas atribuições se não enquadrassem, substancialmente, naquela lista, ainda que os referidos empregados possuíssem qualificações pessoais capazes de, aparentemente, justificar êsse enquadramento. Isto por que a finalidade do inquérito, segundo se esclareceu, era apurar o salário atribuído à efetiva execução de determinadas funções, independentemente das possíveis qualificações pessoais dos que as executassem. Advertiu-se aos entrevistadores de que o item "horas semanais de trabalho" era considerado de suma importância para os resultados do inquérito, uma vez que as comparações de salário seriam posteriormente feitas na base do período semanal, legal, de trabalho, do funcionalismo público federal. As pesquisas não poderiam deixar de levar igualmente em consideração, entretanto, certos benefícios, de ordem econômica, que o empregado recebe em razão do seu cargo, e os quais, de um modo ou de outro, constituem uma forma de remuneração dẹ trabalho. E' óbvio que o empregado que recebe refeições gratuitas ou indumentária de serviço, está tendo um acréscimo sôbre os seus salários. As vantagens dessa ordem necessitam ser igualmente computadas e somadas ao montante em dinheiro que o empregado recebe dos cofres da emprêsa porque é o total assim obtido que exprimirá o valor real dos seus salários. 
Também nesse sentido instruções pormenorizadas foram dadas aos entrevistados. Adiantou-se-1hes, por exemplo, que na coluna " $E$ " do questionário sòmente registrassem o valor estimativo das refeições fornecidas gratuitamente ao empregado pela Organização, cuidando para que na estimativa do valor das refeições fôsse considerado, sempre que tais informações pudessem ser obtidas, o custo exato das mesmas para o empregador. O entrevistador foi prevenido para que não tentasse qualquer estimativa na base do quanto tais refeições poderiam ter custado ao empregado, caso êle as fizesse às suas próprias expensas, porque o levantamento objetivava conhecer apenas quanto tais refeições teriam efetivamente custado ao empregador. No que toca ao valor estimativo mensal do alojamento ou habitação fornecida ao empregado pela Companhia sob a responsabilidade financeira desta última, iguais anotações deveriam ser feitas, indicando-se o caráter geral da acomodação ou alojamento fornecido (casa, apartamento, dormitório, etc.), mas não incluindo, em nenhuma hipótese, o alojamento fornecido se, como resultado da habitação nas cercanias da emprêsa, o empregado ficasse sujeito a chamadas fora de hora, visto que neste caso o empregador estava fornecendo habitação para sua própria conveniência (exemplo típico desta situação ocorre com os zeladures de edifícios).

As pesquisas, entretanto, como já ficou anteriormente esclarecido, deveriam estender-se à obtenção de informações relativas às vantagens adicionais, recebidas pelo empregado, de natureza não econômica. ou pelo menos impossíveis de ser convertidas em expressão monetária. Questionários especiais se elaboram para êsse fim. Do mesmo modo instruções detalhadas se fornecèram sôbre a forma de preenchê-los. Pareceu necessário à Comissão, a fim de evitar equívocos impossíveis de ser corrigidos a posteriori, esclarecer que entre os diversos tipos de benefícios para os quais se desejava obter informações, alguns estariam já previstos em lei, sendo a sua concessão, por parte

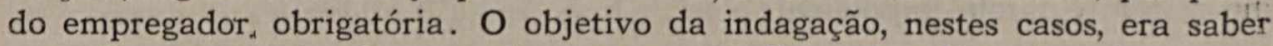
se a firma entrevistada concedia vantagens adicionais, além daquelas que a legislação estipulava.

Também esclareci que a pesquisa se estendeu às organizações de direito público, tais como os governos estaduais e os governos municipais das Capí tais dos Estados. Nos anexos do relatório os interessados em conhecer a má neira como se procedeu ao levantamento dêsses dados encontrarão farta đocumentação constituída de modelos de questionários, gráficơs estatísticos, quadros e tabelas diversas.

Obtidos de volta os questionários, iniciou-se o estudo e análise dos rẹ sultados finais do levantamento.

$\mathrm{Na}$ análise estatística então empreendida, adotaram-se como promédios descritivos dos salários, os $10^{\circ}$ e $3 .^{\circ}$ quartis e a mediana, à vista de melhor. descreverem os grupos de salários ou contingentes existentes abaixo ou acima dos mesmos. Desprezaram-se, pela distorção infalivel que emprestaria aQ. resultado dos estudos, os mínimos e máximos encontrados em cada caso.

Um mapa descritivo foi cuidadosamente levantado com base nesse cri tério estatístico. Nesse quadro, convém explicar, a primeira coluna se obteve pela média aritmética dos valores mencionados na explicação precedente 
(Q1, Md, Q3 ), referentes aos dados do Distrito Federa1 e São Paulo. A segunda coluna consiste nos dados da coluna anterior, porém transformados em percentagens, sendo estas tomadas à base de um índice 100 que representa o-salário mínimo rèspectivo. Na terceira coluna figuram os salários médios percentuais, ponderados, referentes aos Estados que ali se indicam. A ponderação foi éstabelecida à vista do número de empregados cujos salários foram arrolados no levântamento. Ainda aqui os dados apresentados são percentủais à base do índice 100 (representativo do salário mínimo), como na colüria anterior. Os dados da quarta coluna foram obtidos pelo mesmo procésso acima indicado, à vista, porém, dós dados pesquisados para tôdas as Unidade da Federação, exceção feita daquelas onde o número de casos fôsse inferior a dez. Os índices de salário mínimo utilizados são os vigentes antefiormente ao Decreto n. ${ }^{\circ} 35.450$, de $1-5-54$.

Com os dados assim obtidos, iniciou a Comissão os estudos destinados à elaboração da Escala final de remuneração.

A conclusão dêsses estudos se consubstanciou na tabela que figura à página 100 do Diário do Congresso.

Vejamos porém, com os pormenores possíveis, como se chegou à construção dessa tabela.

A despeito do desejo que tenho de informá-los, tanto mais pormenorizadamente quanto possível, sôbre a tabela de vencimento - que afinal deve constituir assunto da maior magnitude - verifico que o tempo de que disponho já se torna relativamente exíguo.

- Tentemos, contudo, um estudo do mapa que se encontra à pág. 100 do Diário do Congresso.

E' óbvio que tentar justificar essa tabela dentro dos poucos minutos que me restam é tarefa impossível.

Vou tentar examiná-la sob os seus aspectos mais importantes.

- Inicialmente convém lembrar um ponto fundamental. Em matéria de técnica de elâboração de escalas de remuneração há dois caminhos'a seguir: a -adoção do sistema de salários fixos ou a adoção do regime de vencimentos variáveis, a que os americanos denominam, respectivamente, "single rate" e "rate range".

Ambos oferecem vantagens típicas, e desvantagens óbvias. E' claro que 0 método de salário fixo contribui para simplificar a elaboração das fôlhas de pagamento, contando com a preferência dos responsáveis pela contabilitade. Nas Emprêsas Industriais ela facilita enormemente os estudos de estimativa de custo. Nas Emprêsas privadas, onde o sistema de remuneração é bașeado no regime de incentivo na base de produção por peça, é claro que o método de vencimento fixo contará com absoluta preferência. O sistema de salário variável contudo, traz vantagens apreciáveis. Considerando a sistemática que informa o plano de classificação, e tendo em vista que a promoção se fará sempre de um cargo de menor dificuldade para outro mais complexo, e portantơ exigihdo qualificações diferentes do servidor, é natural que pensemos numa maneira de compensar os servidores que, embora não preenchiendo as condições necessárias para a promoção ou o acesso, tenham, entre- 
tanto, revelado merecimento no cargo que presentemente ocupam. E ao mesmo tempo uma forma de reconhecer e compensar a experiência que o tirocínio deu ao referido servidor.

Assim, a promoção tem a significação de uma nova nomeação e significa, de fato, que a administração, reconhecendo em seu servidor qualificações para exercer um cargo de maior responsabilidade na organização, resolve prcmovề-lo para êsse cargo. Pode acontecer porém que a administração, embora não constatando em certo servidor méritos reais para promovê-lo, reconheça nêle, entretanto, uma dedicação ao serviço, um zêlo funcional, uma aplicação tais que julgue razoável conceder-lhe uma melhoria-prêmio de salário, sem que isto signifique provê-lo noutro cargo.

Com base nessa idéia, deliberou a Comissão adotar o método de salário variável, pelo qual se entende que cada cargo, ao invés de um vencimento fixo, terá uma sequiência de vencimentos. Para facilitar a estruturação de um método como o descrito, elaborou-se a Escala ou Tabela que os senhores vêem à pág. 100 do Diário do Conǵresso de 11-9-53 - Suplemento.

Por essa escala, teremos 18 níveis, mas cada um dêsses níveis se subdivide, horizontalmente, numa série de graus, ou "referências", como são ali denominados. Todos os cargos públicos, daqui por diante, deverão ser enquadrados num dêsses níveis. Seja, por exemplo, o Oficial de Administração: Como se sabe a ocupação denominada Oficial de Administração, dada a variedade de atribuições que a caracteriza, foi considerada como sendo uma série de classes, composta de três classes: A, B e C. Como sabem, também, em cada uma dessás classes estão grupados cargos de diferente nível de dificuldade. Por isso entendeu a Comissão, segundo a avaliação a que procedeu, de enquadrá-los, respectivamente, nos níveis, 11,13 e 15 . Temos, pois que na carreira ou "Série de Classes" de Oficial de Administração, a classe inicial está enquadrada no nível 11. Entretanto, quanto vale, em dinheiro, o nível 11? Abram a tabela e aí verão: Vencimento Base: $6.900,00-\mathrm{Na}$ realidade, porém, isso seria um salário fixo. E o método adotado, como vimos, foi o de salários variáveis. Temos pois que o nível 11 , na realidade, tem um vencimento variável, ou seja, uma Escala, ou um "rate range", que vai de $\mathrm{Cr}$ \$ $6.900,00$ a 8.400 .00 . Isto pôsto, um Oficial de Administração "A" que supostamente jamais se habilitasse a ocupar o cargo mais difícil de Oficial de Administração "B", nem por isso teria uma situação estanque pois que, com o correr dos anos, - desde que revele condições mínimas de merecimento para continuar no exercício do cargo, - irá paulatinamente progredindo e ao fím de certo tempo estará ganhando não mais $\operatorname{Cr} \$ 6.900,00$, e $\operatorname{sim} 8.400,00$.

Esta progressão, entretanto, deverá ocorrer automàticamente, e como não se trata de movimento de funcionário de um cargo para outro, mas de simples melhoria de salário no mesmo cargo, ela não depende de existência de vaga, nem é competitiva, o que significa, que, havendo 50 ou 100 funcionários no vencimento-base de Oficial de Administração "A" - $\operatorname{Cr} \$ 6.900,00$, ao fim de 3 anos todos passatão à referência I do mesmo nível, ou seja, $\mathrm{Cr} \$$ 7. 150,00 . 
Em todos os níveis o número de progressões horizontais é o mesmo. Temos, pois. 18 níveis de salário cada um dêles subdividido, horizontalmente em 7 graus (um vencimento-base e 6 melhorias).

E' claro que um dos problemas surgidos ao construirmos a escala foi a questão de decidir: $1^{\circ}$ ) o número de graus, ou referências que deveria ter cada nível e $2 .^{\circ}$ ) o valor de cada melhoria.

Os teóricos da administração de pessoal sustentam longas e por vêzes fastidiosas discussões em tôrno dêstes dois pontos.

$\mathrm{Na}$ prática, porém, a Comissão se viu em face de uma realidade incontestável: as limitações impostas pela capacidade financeira do Erário. Os senhores encontrarão, por exemplo, em certos tratados de administração de pessoal a afirmativa de que cada progressão horizontal não deve ser inferior a $20 \%$ do salário. E' claro que uma progressão de tal ordem seria impraticável, porque nos levaria por exemplo a construir o nível 11 com os seguintes valores: vencimento base $\mathrm{Cr} \$ 6.900,00 ; 6 .^{\mathrm{a}}$ referência $\mathrm{Cr} \$ 20.554,80$.

Considerando que após a $6 .^{a}$ progressão teríamos ainda dois adicionais por tempo de serviço, o oficial de administração após 25 anos de serviço, mesmo sem que tivesse obtido qualquer promoção (no sentido técnico do vocábulo) estaria ganhando mais do que um Ministro de Estado.

Assim foi que a Comissão, ao elaborar essa tabela, se viu face a um conjunto de limitações que eu gostaria, - mas infelizmente não poderei - examinar com detalhe, porque já esgotei o tempo de que dispunha para falar-lhes. Posso, entretanto, em resumo, assim enumerá-los:

a) necessidade de cingir-se a uma despesa total prèviamente determinada.

b) necessidade de estruturar a Escala de modo a permitir um substancial aumento de vencimento nas promoções verticais e acessos.

c) necessidade de construí-la de modo a permitir uma seqüência de meihoria de salário em cada nível.

d) necessidade de dar a tais melhorias um valor razoável.

e) necessidade de limitar essas progressões horizontais ao total de 18 anos, visto que a lei já prevê adicionais após os 20 e os 25 anos de serviçc.

f) necessidade de estabelecer um interstício para essas melhorias automáticas de modo que as mesmas não sobrecarregassem demasiadamente o Erário nem se anulassem pelo efeito da demora (foram assim fixadas 6 melhorias de 3 em 3 anos, ou seja: 18 anos).

g) necessidade de limitar o tôpo da escala em $\operatorname{Cr} \$ 18.000,00$ a fim de permitir, acima dêsse índice, uma disponibilidade para a fixação da remuneraçâo dos cargos de direção.

h) necessidade de limitar a escala ao vencimento dos Ministros de Estado - fixados em lei.

i) conveniência de construir a Escala de modo a que a referência final de cada nível fôsse sempre maior do que a inicial do nível imediatamente 
superior, tendo em vista que é de boa técnica reconhecer que o servidor do nível "A", após certo tempo de experiência, tirocínio, e prática de serviço, pode ser considerado mais útil à administração do que o servidor do nível "B" que acaba de ingressar nesse cargo. Isto pôsto o Oficial de Administração " $\mathrm{A}$ " (nível 11), após 9 anos de serviço ganhará a mesma coisa que o Oficial de Administração classe "B" (nível 13) que acabou de ingressar nesse cargo. Isto deve ser, pelo menos teòricamente, um ponto de vista defensável.

j) necessidade de fazer com que tanto as progressões horizontais, como a diferença vertical de vencimento para promoções e acesso siga em escala crescente (cada vez maior, quanto mais alto o nível).

Com êstes pontos básicos norteando o trabalho, foi que se entregou a Comissão à tarefa de construção da Escala que acabamos de examinar.

Creio haver abordado todos os pontos que mereciam consideração. E' possível que em alguns dêles não tenha descido ao desejado detalhe. Alguns aspectos, talvez, que gostaria de abordar com maior profundidade, ficaram prejudicados dada a exigüidade de tempo.

Quem sabe poderei fazê-lo noutra oportunidade que me seja oferecida de conversar com êste agradável e atento auditório.

Antes de terminar, quero apenas agradecer a atenção que me dispensaram e pedir que me perdoem se fui muitas vêzes pouco explícito e quase sempre demasiado prolixo.

\section{SUMMARY}

1. The A, aimes at an interpretation of the Position Classification and Pay Plan bill which is, at present, pending before Congress. Emphasis is placed on the Pay Plan since the A. has worked as Technical Assessor to the Comission on Position Classification for the sector of the Pay Plan.

2. Position Classilication and Pay Plan as closed related but separate categories not to be confused with each other.

3. The purpose of position classification is to provide an objective and comprehensive picture of each position within the public service, in order to make possible the several phases of personnel administration, viz., selection, placement, training and promotion.

4. Payment of both civil servants and industry employees not based on realistic foundations in the recent past, its criteria senerally subject to the discretion of executives; the interference of the spoils system.

5. The concept of "just salary" and "De Rerum Novarum". The principle of "equal pay for equal work". The movement towards collective bargaining. The emergence of serious studies on the rational planning of wages and salaries.

6. Job evaluation and the scientific basis of pay plans in the history of American industrialism. Strikes often eliminated through adoption of such bases.

7. State intervention in the disputes between management and employees: collective bargaining stimulated, trade unions legalized, the right to strike recognized, the principle of profitsharing postulated, side by side with the institution of minimum wages.

8. The principle of the primary and superior interest of the Administration as contrasted with the erroneous nation of conflictind interests between the Administration and its body of employees. 
9. The necessity of distinguishing between job analysis and job evaluation. The problem discussed. The two elements indispensable for the establishment of a satisfactory pay plani.

10. The complexity of the systems of payment. The premium plan. The concept of living wages. The specific difficulties of a pay plan for the civil service.

11. The ever-changing character of technical management and of advisory activities, thus requiring special payment criteria.

12. The variety of factors to be taker into account in the establishment of a pay plan for the civil service: the systems that prevails in industry; the policies adopted by other covernment agencies; the financial conditions of the treasury; the cost of living.

13. The survey of the actual salaries and wages prevailing in the community as a preliminary step of any position classification and pay plan. Methods of procedure for collecting data.

14. The procedures aciopted by the Comission for such collection of data minutely analyzed. The cooperation of the "Instituto Brasileiro de Geografia e Estatística".

15. The tasks of the sector of Pay Plan of the Comission enumerated and discussed.

16. Criteria adopted by the Commission for the selection of key classes.

17. The areas to be covered by the survey finally determined, being largely restricted to the State capitals. Some municipalities also included in it. Selection of the private companies asked to fill in the questionnaire and to be interviewed.

13. Questionnaires classified into (1) those considered acceptable and ready to be immediately tabutated and (2) those deemed deficient in some respect, thus requiring verification. The latter to be returned for reviewing in their places of origin.

19. The pay plan finally elaboratied on the bases of data thus collected and analyzed. The alternative between the single rate and the rate range systems of payment. The latter sclution adopted. The eighteen grades, each hrizontally dividea into seven steps.

20. Criteria that the Commission had to follow as regards maximum total personnel expenditures, possibility of granting a substantial salary raise, and limitation of top salaries of career positions.

Evitar a crescimento desnecessário do número de servidores, torná-los mais eficientes e melhor remunerados deve ser a linha mestra no tocante à política dé pessoal. Disso depenđe, em grande parte, a elevação dos atuais padrões de eficiência do serviço público.

Gen. Juarez Távora 